Article

\title{
A Stochastic Programming Model for Fuel Treatment Management
}

\author{
Mohannad Kabli ${ }^{1}$, Jianbang Gan ${ }^{2}$ and Lewis Ntaimo ${ }^{1, *}$
}

1 Department of Industrial and Systems Engineering, Texas A \& M University, College Station, TX 77843-3131, USA; E-Mail: kabillo@email.tamu.edu

2 Department of Ecosystem Science and Management, Texas A \& M University, College Station, TX 77843-2138, USA; E-Mail: j-gan@tamu.edu

* Author to whom correspondence should be addressed; E-Mail: ntaimo@tamu.edu; Tel.: +1-979-458-2360; Fax: +1-979-458-4299.

Academic Editor: Eric J. Jokela

Received: 16 March 2015/ Accepted: 29 May 2015 / Published: 15 June 2015

\begin{abstract}
This work considers a two-stage stochastic integer programming (SIP) approach for optimizing fuel treatment planning under uncertainty in weather and fire occurrence for rural forests. Given a set of areas for potentially performing fuel treatment, the problem is to decide the best treatment option for each area under uncertainty in future weather and fire occurrence. A two-stage SIP model is devised whose objective is to minimize the here-and-now cost of fuel treatment in the first-stage, plus the expected future costs due to uncertain impact from potential fires in the second-stage calculated as ecosystem services losses. The model considers four fuel treatment options: no treatment, mechanical thinning, prescribed fire, and grazing. Several constraints such as budgetary and labor constraints are included in the model and a standard fire behavior model is used to estimate some of the parameters of the model such as fuel levels at the beginning of the fire season. The SIP model was applied to data for a study area in East Texas with 15 treatment areas under different weather scenarios. The results of the study show, for example, that unless the expected ecosystem services values for an area outweigh fuel treatment costs, no treatment is the best choice for the area. Thus the valuation of the area together with the probability of fire occurrence and behavior strongly drive fuel treatment choices.
\end{abstract}


Keywords: fuel treatment; wildfire behavior; wildfire risk; optimization; stochastic integer programming

\section{Introduction}

Economic and human losses have continued to increase due to the rise in the number of wildfires, which call for solutions to alleviate the risks $[1,2]$. Fuel treatment is a process of reducing fuel levels to mitigate the impact of future fires and is typically performed before the beginning of a fire season. However, fuel treatment has received mixed views in the literature and its effectiveness in reducing the negative consequences of wildfire is still debatable. This paper takes a stochastic optimization perspective and devises a model for fuel treatment planning for rural forests in East Texas to study the impact of fuel levels and values at risk (in terms of ecosystem services provided by the land) on fuel treatment options.

There are different fuel treatment methods and each has its own advantages and disadvantages. In this work, three main fuel treatment types are considered; prescribed fire or prescribed burning, mechanical thinning, and grazing. Prescribed fire is a popular method and is the deliberate use of fire to burn understory vegetation with a goal of reducing surface fire spread. However, this method has to be done when weather conditions are favorable and precautions have to be carefully taken when to avoid escaped fires. Mechanical thinning is the removal of fuels such as branches, limbs, trees, and tree crowns using mechanical equipment. Thinning can be broken down into three types [3]; low thinning, crown thinning, and selection thinning. Low thinning removes small trees on the surface level, while crown thinning removes large trees and trims the crowns. Selection thinning removes the least desirable trees. Unlike prescribed burning, mechanical thinning can be done in a variety of weather conditions but can be expensive due to the number of workers needed and the use of expensive equipment. Grazing as a fuel treatment method involves using herds of livestock (e.g., cattle, sheep or goats) to consume forage and reduce fuel levels. This method is typically used in grasslands, can take several days, and is relatively inexpensive compared to prescribed fire and mechanical thinning. Other methods of fuel treatments include the use of chemical herbicides to slow down the growth of plants, but may have potential to negatively affect the environment.

Many researchers suggest that fuel treatment helps in reducing the severity of fire. Safford et al. [4] support fuel treatment based on the studies of the area affected by the Angora fire in 2007, which is considered as one of the ten largest fires in US history. The work by Bradstock et al. [5] suggests that fuel treatment should be assessed when there is severe weather, were the impact of the fire is the most. The work done by Hudak et al. [6] demonstrates the importance of fuel treatment by evaluating its effectiveness using case studies carried out in several forests and rangelands. In general, if fuel treatment is not implemented it can lead to more intense fires and more economic and life losses. The primary objective of fuel treatment is to make fire less severe rather than reduce its extent to make it easier to suppress. Finney et al. [7] devise a model to optimize the selection of areas for treatment. A minimum travel time algorithm is used to maximize the minimum distance a fire travels across a landscape. The areas are selected so that the collective interaction between them aids in hindering the rate of fire spread. 
Finney [8] considers different shapes and patterns of fuel treatment on disconnected spots. The aim is to reduce the rate of spread and fireline intensity. However, simulation results indicate marginal reductions in both fire behavior characteristics. The work by Loehle [9] also comes to similar conclusions as the findings by Finney.

This paper was motivated by the limited number of stochastic optimization models in the literature that incorporate crucial stochastic factors such as weather and vegetation growth to study the economic impact of fuel treatment planning. Closely related works include the work of Wei et al. [10] and Wei [11] who consider the allocation of fuel treatment to minimize future expected losses using a mixed-integer programming (MIP) model. The model selects the most suitable fuel treatment at each area under consideration and takes into account of wildfire risk which includes three components; probability of burn for each area, probability of fire spreading into the next adjacent area, and conditional probability of fire spreading from an ignited area into an adjacent. Rytwinski and Crowe [12] also consider an MIP model to minimize the total expected losses from fire under budget constraints. They divide an area under study into several cells and the expected loss is the probability of a cell burning multiplied by the loss for that cell.

More recently, Minas et al. [13] devise an IP model that considers both fuel treatment and fire suppression preparedness because of the strong interrelation between them. This work proposes an integrated planning framework which is demonstrated using a series of hypothetical test landscapes. In Minas et al. [14] an MIP model is devised for multi-period scheduling of fuel treatments. This model allows for landscape heterogeneity and ecological and operational considerations and constraints. The work examines different patterns of fuel treatments with the objective of slowing down spread of fire. Other works include Trunfio et al. [15] who propose a computational approach that for a spatially-optimized treatment layout exploiting tabu search and computing using graphics processing units.

This work considers a two-stage stochastic integer programming (SIP) model for optimizing fuel treatment planning for rural forests and shows that fuel treatment is favorable for areas with high values at risk as well as high fuel levels that can potentially lead to large fires. The model explicitly accounts for the different weather scenarios and is based on master's thesis work by Kabli [16]. A fire behavior model and a wildfire risk model are incorporated in this approach to estimate some of the parameters of the SIP model, which include fuel levels at the beginning of the fire season. The objective of the model is to minimize the here-and-now total costs of fuel treatment in the first-stage, and the expected costs associated with the impact from potential fires in the second-stage based on the fuel treatments done in the first-stage. The SIP model considers a set of treatment areas, a choice of fuel treatment options, and includes budgetary and labor constraints. It was applied to data for a study area in East Texas with arbitrarily selected 15 treatment areas involving different weather and fire occurrence scenarios. This area is managed by the Texas A\&M Forest Service (TFS).

The rest of this paper is organized as follows: In Section 2 we give an overview of the SIP approach, describe the study area, derive the SIP model, and then discuss the software implementation and design of experiments for the study. The results and discussion are given in Section 3 and the paper ends with concluding remarks and future work in Section 4. 


\section{Models and Methods}

\subsection{Overview}

The proposed SIP approach for fuel treatment planning integrates vegetation growth, fire behavior, and wildfire risk as depicted in Figure 1. The fuel treatment options include no treatment, prescribed fire, mechanical thinning and grazing. Vegetation growth is modeled using a plant growth modeling software such as the Phytomas Growth Model (PHYGROW) [17] while fire behavior is modeled using a fire behavior software such as FARSITE [18]. A wildfire risk model such as the Texas Wildfire Risk Assessment System (TWRAS) [19] is used to compute wildfire risk parameters of interest, which become inputs to the two-stage SIP model for optimizing fuel treatment plans. The two-stage SIP model determines the fuel treatment plan under uncertainty in fuel levels, weather, and wildfire risk. The fuel levels at any given time can be estimated using a vegetation growth model, for example, while wildfire risk is estimated based on weather and fire behavior. Given the appropriate input data, the SIP model optimizes the here-and-now fuel treatment cost in the first-stage and the expected future costs in the second-stage, which account for the impact of the fuel treatment options selected in the first-stage. Thus the fuel treatment plan specifies the optimal type of fuel treatment for area.

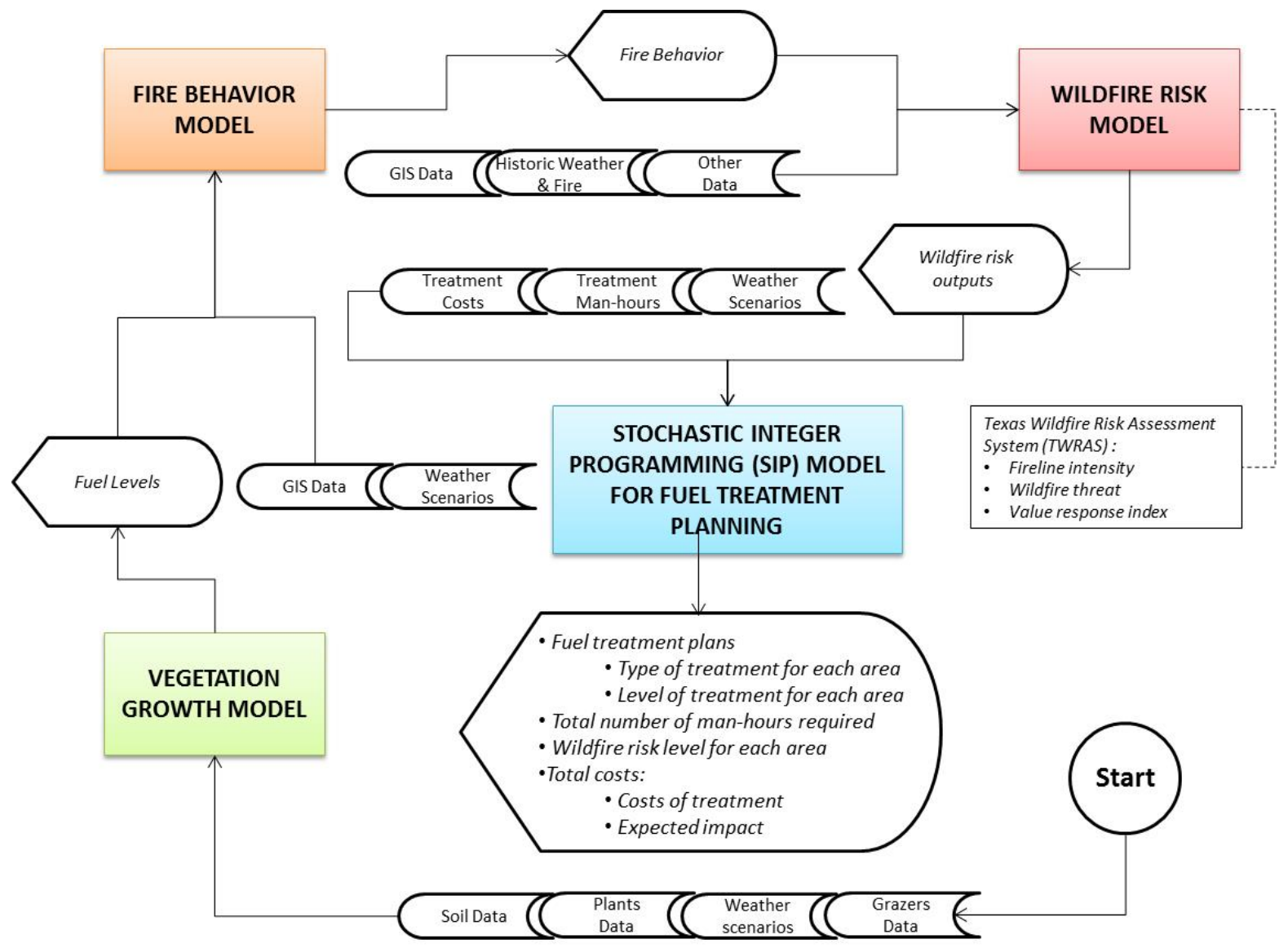

Figure 1. Schematic diagram of the stochastic integer programming (SIP) methodology. 


\subsection{Study Area}

The SIP model was applied to a study area called Texas District 12 (TX12) located in East Texas, USA (Figure 2), which is under the jurisdiction of Texas A\&M Forest Service (TFS). The historical fire data for TX12 shows a total of 13,163 fire occurrences in the period 1985-2006 [20]. Clearly TX12 is susceptible to wildfires and certain areas of this region can benefit from fuel treatment. To perform our study, 15 areas for fuel treatment (Figure 3) were selected. These areas had similar vegetation of grass and shrubs and each was arbitrarily set to be about 200 hectares (ha). The areas were chosen with enough distance among them so that they are isolated to prevent any interactions in terms of fire spread. The vegetation growth, fire behavior, and wildfire risk models generate the estimated parameters for the SIP model. However, these models require several field data. Particularly, data describing the landscape, scenario weather, soils, and plants are needed. The data that were available at the time of the study were supplied by the TFS. The type of vegetation in TX12 area includes Northern Forest Fire Laboratory (NFFL) [21] fuel models 2, 3, 4, 6, 7, 8 and 9. Table 1 defines each of these fuel models [21], and Table 2 shows the dominant fuel models in each area.

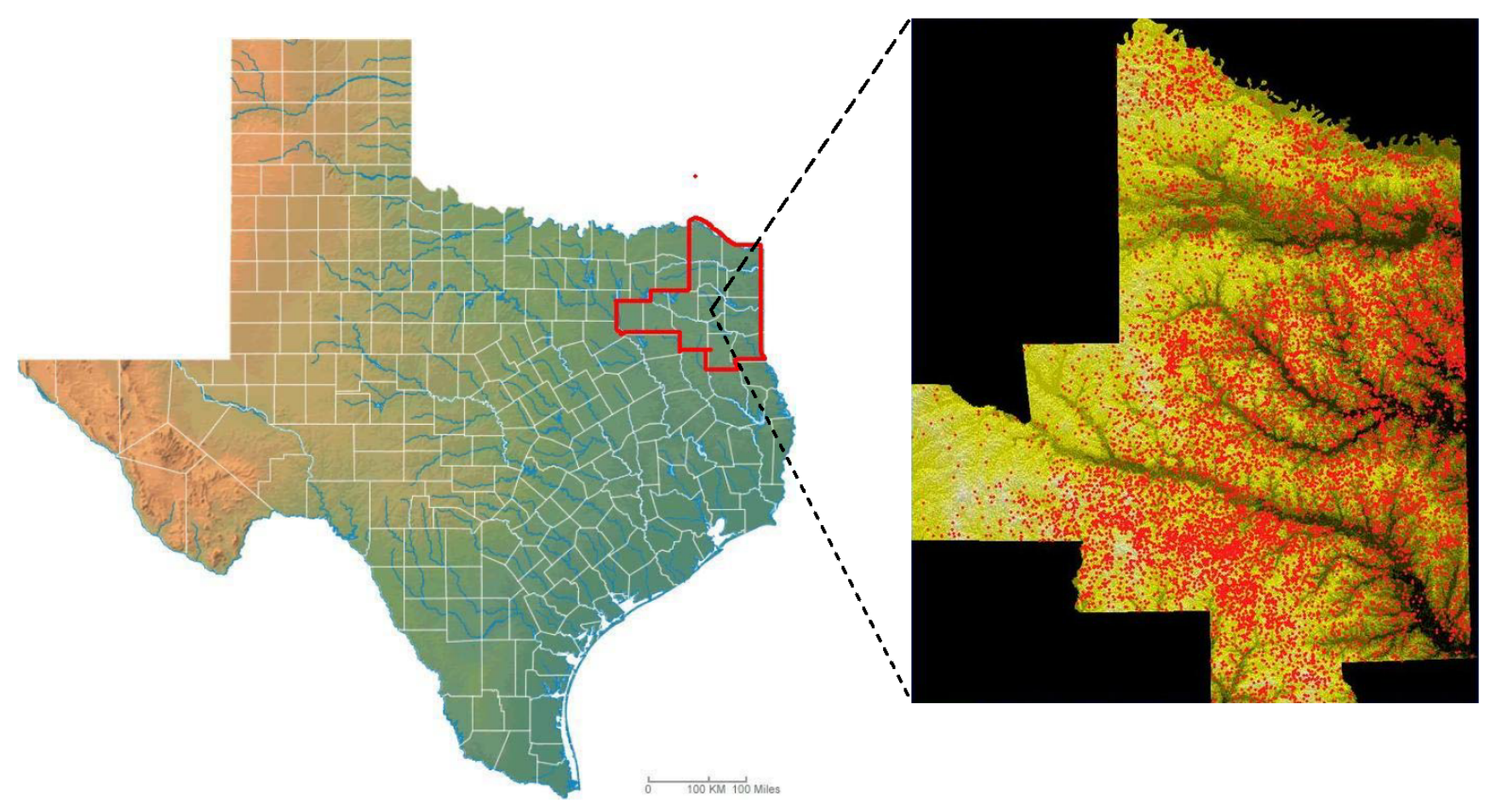

Figure 2. Location of Texas District 12 (TX12) in East Texas [22] and historical fire occurrences, where each dot represent a fire occurrence. 


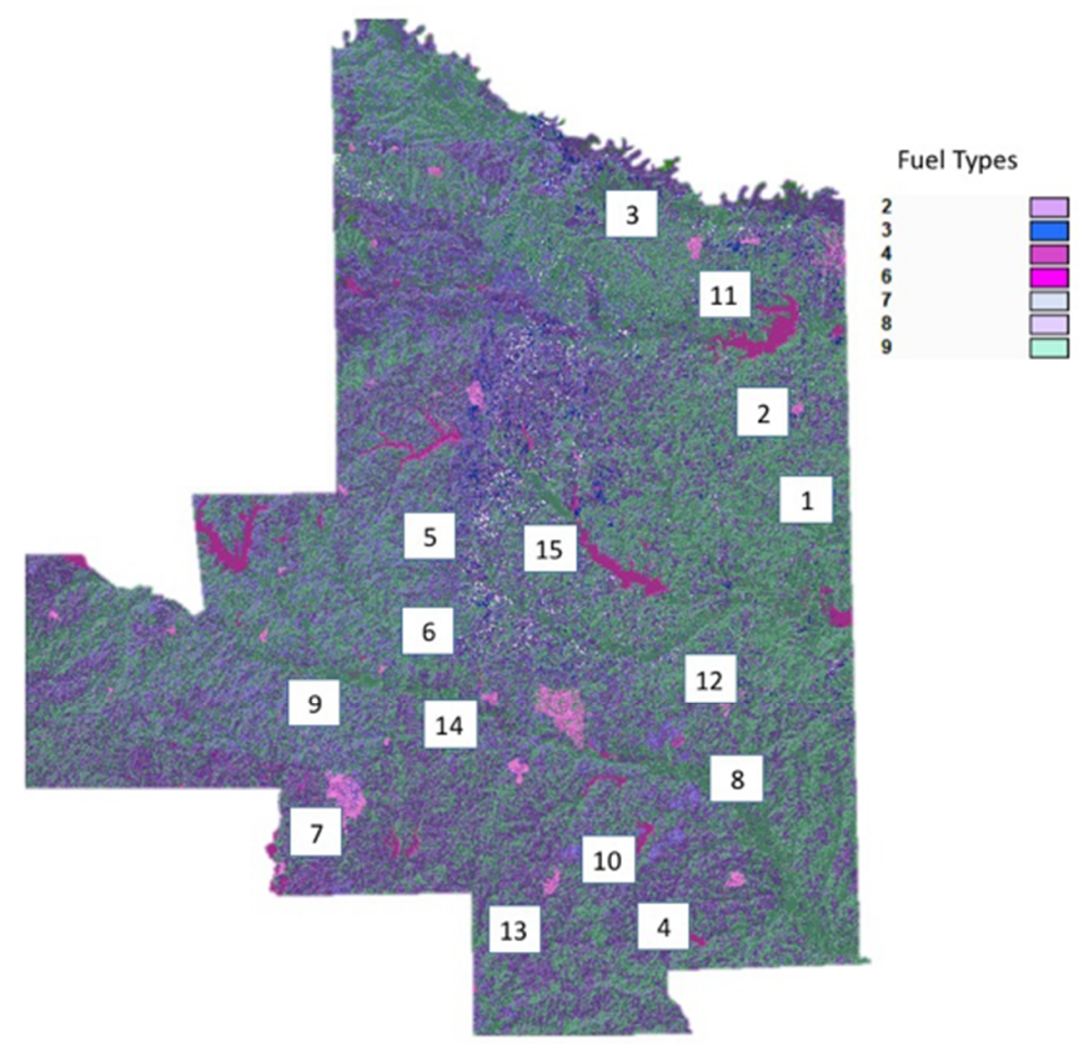

Figure 3. Selected potential areas for fuel treatment.

Table 1. Fuel models description.

\begin{tabular}{ccccc}
\hline \multirow{2}{*}{ Fuel Model } & \multirow{2}{*}{ Typical Fuel Complex } & \multicolumn{3}{c}{ Fuel Loadings } \\
\cline { 3 - 5 } & & Fuel 1-Hr & Fuel 10-Hr & Fuel 100-Hr \\
\hline 2 & Timber (grass and understory) & 2 & 1 & 0.5 \\
3 & Tall grass (2.5 feet) & 3.01 & 0 & 0 \\
4 & Chaparral & 5.01 & 4.01 & 2 \\
6 & Dormant brush, hardwood slash & 1.5 & 2.5 & 2 \\
7 & Southern rough & 1.13 & 1.87 & 1.5 \\
8 & Closed timber litter & 1.5 & 1 & 2.5 \\
9 & Hardwood litter & 2.92 & 0.41 & 0.15 \\
\hline
\end{tabular}

\subsection{SIP Model Description}

The goal of the two-stage SIP fuel treatment model is to reduce the here-and-now costs of implementing fuel treatment for a set of selected areas and the expected impact of wildfire measured in dollars. Four fuel treatment options are considered: no treatment (NT), prescribed fire (PF), mechanical treatment (MT), and grazing (G). The no treatment option is assigned to an area if that area cannot be treated because it is not beneficial to do so based on values at risk or if there is other areas that have more priority (e.g., have higher values at risk and fuel levels), or due to budgetary and labor constraints. In the SIP model, the study area is divided into a set of areas to be treated and each area is subdivided into cells of the same size with similar vegetation type and landscape conditions. Each area is a candidate for all or a subset of fuel treatment options depending on what is appropriate for the area. Then the type of fuel 
treatment is determined by the SIP model under budgetary and labor constraints. The percentage reduction levels for grazing and mechanical treatment are assumed to be 20 or 35 percent. Also, it is assumed that prescribed fire eliminates all undesired fuels in a given cell. The fuel or vegetation levels for each scenario are assumed to be known at the beginning of the fire season. This is done through field studies and GIS data. These fuel levels are configured into the fire behavior simulation, which is then used to simulate the burn of each cell to record the final fire perimeter, fire area, fireline intensity and heat content. These outputs are used along with other measures to determine the wildfire risk rating for each cell. We also allow for the option of using a vegetation growth model such as PHYGROW to estimate the fuel levels at a given point in time. PHYGROW simulates the growth of understory vegetation under different scenarios to account for the uncertainty of weather and soil conditions.

Table 2. Dominant fuel models in each area.

\begin{tabular}{ccc}
\hline Area Number & First Dominant Fuel & Second Dominant Fuel \\
\hline 1 & 9 & - \\
2 & 2 & 9 \\
3 & 9 & 2 \\
4 & 9 & 2 \\
5 & 8 & 2 \\
6 & 8 & 2 \\
7 & 2 & - \\
8 & 9 & 2 \\
9 & 8 & 9,2 \\
10 & 9 & 2 \\
11 & 9 & 3,2 \\
12 & 9 & 2 \\
13 & 2 & - \\
14 & 9 & 2 \\
15 & 9 & 8,2 \\
\hline
\end{tabular}

The objective of the SIP model is to minimize the total costs of fuel treatment and the expected impact from potential fires based on the fuel treatment carried out. The fuel treatment costs in the model include direct labor and the cost of equipment. The impact from potential wildfires is the values-at-risk includes endangered species losses, carbon emissions, and soil erosion. We refer to this as the ecosystem services provided by the rural forests in terms of dollars. To mathematically state the SIP model, we first describe our notation and then give the formulation.

Sets

$\Omega \quad$ Set of all scenarios (based on weather conditions, fuel loadings)

I Index set for fuel treatment types

$J \quad$ Index set for treatment areas

First-Stage Decision Variables

$$
x_{i j} x_{i j}=\left\{\begin{array}{c}
1, \text { if area } j \in J \text { is treated with fuel treatment } i \in I \\
0, \text { otherwise }
\end{array}\right.
$$

First-Stage Parameters: 
$d_{i j-N u m b e r}$ of man-days necessary to do fuel treatment $i \in I$ at area $j \in J$

$D$-Total number of man-days available for performing fuel treatments

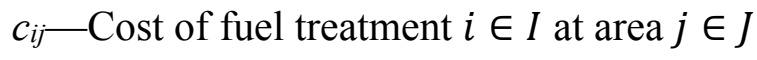

$B$-Maximum budget available

Second-Stage Decision Variables

$y_{i j}^{\omega} y_{i j}^{\omega}=\left\{\begin{array}{c}1, \text { if area } j \in J \text { receiving treament } i \in I \text { has relatively low wildfire threat } \\ 0, \text { otherwise }\end{array}\right.$

\section{Second-Stage Parameters}

$\widetilde{\omega}$ Random variable whose outcome/scenario is $\omega \in \Omega$

$p_{j}^{\omega}$ Probability of fire occurrence in area $j \in J$ under scenario $\omega \in \Omega$

$g_{i j}^{\omega}$ Potential dollar impact of fire for area $j \in J$ receiving treatment $i \in I$ under scenario $\omega \in \Omega$

$T$ Threshold for wildfire threat

$W T_{i j}^{\omega} \quad$ Wildfire threat level for area $j \in J$ that was treated with fuel treatment $i \in I$ under scenario $\omega \in \Omega$

The overall objective of the two-stage SIP model can now be stated as follows:

$$
\text { Minimize } \sum_{i \in I} \sum_{j \in J} c_{i j} x_{i j}+E[h(x, \widetilde{\omega})],
$$

where $c_{i j}$ is the first-stage cost of fuel treatment type $i \in I$ (no treatment, prescribed fire, mechanical thinning, grazing) for area $j \in J$. Thus the first-stage here-and-now cost $\sum_{i \in I} \sum_{j \in J} c_{i j} x_{i j}$ is the total cost of performing the fuel treatments. The second-stage cost $E[h(x, \widetilde{\omega})]$ is the expected dollar cost of the impact of potential fires in terms of the loss of ecosystem services provided by the forest. For each realization $\omega \in \Omega$ of $\widetilde{\omega}$, the second-stage objective function is given as follows:

$$
h(x, \omega)=\operatorname{Minimize} \sum_{i \in I} \sum_{j \in J} p_{j}^{\omega} g_{i j}^{\omega}\left(1-y_{i j}^{\omega}\right) \text {. }
$$

This objective function minimizes the expected ecosystem services impact after fuel treatment based on fires occurring under scenario $\omega$. The cost of impact $g_{i j}^{\omega}$ is estimated for each treatment area. This value represents the ecosystem services losses for that area plus the expected losses for adjacent areas, if any, conditioned on the assumption that if a fire occurs in a given area, it can potentially spread to an adjacent.

The first-stage includes three main constraints. The first set of constraints restricts one type and level of treatment to be implemented in each area and is given as

$$
\sum_{i \in I} x_{i j}=1 \forall j \in J \text {. }
$$

The second constraint meets the requirement that the total cost for fuel treatment must not exceed the maximum budget available and is given as

$$
\sum_{i \in I} \sum_{j \in J} c_{i j} x_{i j} \leq B
$$


This constraint can be ignored if there is no budgetary restriction, especially when trying to assess the best fuel treatment option assuming money is not as issue. The third constraint imposes a restriction on the number of labor days allocated for implementing all the fuel treatments and is given as

$$
\sum_{i \in I} \sum_{j \in J} d_{i j} x_{i j} \leq D
$$

Finally, the binary restrictions on the first-stage decision variables are given as follows:

$$
x_{i j} \in\{0,1\}, \forall i \in I, j \in J .
$$

The second-stage has the following set of constraints to capture the wildfire threat level for each area:

$$
y_{i j}^{\omega} \leq x_{i j}\left(\frac{T}{W T_{i j}^{\omega}}\right) \forall i \in I, j \in J
$$

In Constraint (6), $W T_{i j}^{\omega}$ is the wildfire threat level for area $j \in J$ receiving treatment $i \in I$ under scenario $\omega$ and $T$ is the maximum wildfire threat value allowed. Thus the decision variable $y_{i j}^{\omega}$ assumes a value of 1 if the ratio $\frac{T}{W T_{i j}^{\omega}} \geq 1$ for treatment $i \in I$ selected in the first-stage. Finally, the binary restrictions on the second-stage variables are given as follows:

$$
y_{i j}^{\omega} \in\{0,1\} \forall i \in I, j \in J .
$$

Given a finite number of scenarios, the two-stage SIP model can be written as a large-scale deterministic equivalent problem (DEP). This problem is an IP and can be solve using an off-the-shelf MIP optimization software solver.

\subsection{Software Implementation and Design of the Experiments}

The SIP model was implemented and solved using CPLEX 12.1 [23] based on TX12 data that was available at the time of this study. FARSITE was used to obtain fire behavior data and other data were obtained from the literature. These data include the probabilities for fire occurrence in TX12, the estimated potential impact (ecosystem services losses) in dollars per hectare based on the area burned, the costs of applying each level of fuel treatment at each area under study, and the expected number of days necessary to perform each type and level of fuel treatment. We used the probability of fire occurrence in the range of 0 to 0.12 based on a previous study for East Texas [24]. A base rate of \$593/ha was used for ecosystem services losses based on a previous study for Texas [25]. The expected ecosystem services cost in the model for a given weather scenario was calculated by multiplying this rate by the probability of fire occurrence and the estimated burned area from FARSITE. PHYGROW was not used in this study because input data for this model could not be obtained at the time of this study. Therefore, fuel loadings used in FARSITE were based on historical GIS data from 2007. These fuel loadings were considered as the vegetation levels at the beginning of the fire season. For this study, two levels of fuel treatment were considered for grazing and mechanical removal (20\% and 35\%). Since prescribed fire was assumed to eliminate all fuels, it was assigned only one level of fuel treatment $(100 \%)$. These levels were accounted for in FARSITE by assigning a new fuel model based on the fuel desired to be altered or by changing the fuel loading values as needed. Areas treated with prescribed fire were assumed to regain $40 \%$ of their fuel volume at the beginning of the next fire season. 
Three weather scenarios were considered, moderate, high, and extreme. The probability of occurrence of each weather condition was assumed to be almost equally likely (Table 3). The costs and number of days required for each type of fuel treatment were based on literature sources [26-29]. For our experiments we used the values summarized in Table 4. The treatment cost for each fuel treatment type was assumed to be the same for each area. In reality, however, the same type of fuel treatment can vary for different areas depending on certain factors such as the vegetation and topography of area. For this study, fireline intensity was used as the wildfire threat measure and a base threshold value of $1000 \mathrm{~kW} / \mathrm{m}$ was used based on the study by Duguy et al. [30]. These authors considered fireline intensities larger than this number to be of extreme intensity, that is, high in wildfire threat. The total budget and number of man-days available were assumed to be $\$ 1,000,000$ and 1200 days, respectively. These values were arbitrarily chosen based on the maximum number of days and maximum budget needed to implement prescribed fire.

Table 3. SIP model scenario data.

\begin{tabular}{ccccc}
\hline & Weather Scenarios & Moderate & High & Extreme \\
\cline { 2 - 5 } 1 & Wind speed (mph) & $4-6$ & $12-15$ & $15-18$ \\
& Humidity (\%) & $40-60$ & $35-50$ & $30-45$ \\
& Temperature (degrees Fahrenheit) & $60-80$ & $60-80$ & $60-80$ \\
& Probability of occurrence & 0.33 & 0.33 & 0.34 \\
\hline \multirow{2}{*}{2} & Fire occurrence under each weather scenario & Yes & No & \\
& Probability of occurrence & 0.043 & 0.957 & \\
\hline
\end{tabular}

Table 4. Fuel treatment costs.

\begin{tabular}{cccc}
\hline Treatment Type & MT & PF & G \\
\hline Cost $(\$ /$ ha $)$ & 1112 & 384 & 182 \\
Area per day (ha/day) & 0.404 & 0.81 & 1.07 \\
\hline
\end{tabular}

Based on the three weather scenarios and fire occurrence for each (Table 1) we created several instances of the SIP model with a total of six scenarios by varying the base rate of $\$ 593 /$ ha for ecosystem services losses as well as the fireline intensity threshold value of $1000 \mathrm{~kW} / \mathrm{m}$. The ecosystem services value base rate was multiplied by a factor (e.g., 1, 50, and 100) to see the impact on the fuel treatment options as the value of the land is increased. The fireline intensity threshold was varied from 500 to 5000 to study the sensitivity of the treatment plans to the level of wildfire threat. Several instances were created and solved using the CPLEX MIP solver. Each run took less than a minute to solve since the number of treatment areas and scenarios is fairly small for this set of experiment runs. The goal was to get some preliminary insights into how ecosystem services values and wildfire threat influence fuel treatment planning.

\section{Results and Discussion}

A sample of the computational results are reported in Tables 3-5 for a fireline intensity threshold value of $1000 \mathrm{~kW} / \mathrm{m}$ and ecosystem services factors of 1,50 , and 100, respectively. The first column of the table lists the treatment areas and the next six columns show the treatment options. The last two columns list the treatment cost and expected impact (ecosystem services losses) for each area based on the 
selected fuel treatment type. An "X" means that the treatment option corresponding to that column was selected as the optimal choice. As can be seen in Table 5, with a base ecosystem services value of $\$ 593 /$ ha, which is the average for Texas, no fuel treatment is the optimal choice. This means that it is not economical to perform fuel treatment to any of the 15 areas at this level of ecosystem services valuation of the areas. However, as we increase this base value in Tables 6 and 7, we see that fuel treatment is favored in certain areas and the type of fuel treatment is selected based on which one will provide the best benefits.

The optimal type of fuel treatment for each area differs due to several reasons. For example, wildfire threat in some areas can only be reduced by removing large volumes of fuel. Therefore, such areas are given priority for fuel treatment. The model assigns fuel treatment choices to areas with relatively high ecosystem services values and low fireline intensity thresholds to render the areas safe from potential fires. Sensitivity of the budget and total labor days available were both examined and the results showed that fuel treatment choices can be limited by the available budget and labor days. Also, the sensitivity of the fireline intensity threshold was also examined and it was observed that the treatment plans were fairly sensitive to this value. Increasing the threshold rendered some areas safe which allowed more fuel treatments to be done in other areas. These preliminary results shows that fuel treatment can actually provide value for rural forests such as those in TX12 as long as the value of the land is high enough to justify the cost of fuel treatment. Furthermore, the wildfire threat or fireline intensity threshold used has a strong influence on the fuel treatment choices.

Table 5. Fuel treatment plan based on an ecosystem services factor of 1 and fireline intensity threshold of $1000 \mathrm{~kW} / \mathrm{m}$.

\begin{tabular}{|c|c|c|c|c|c|c|c|c|}
\hline Area & NT & MT 20\% & MT 35\% & PF $100 \%$ & G 35\% & G $20 \%$ & $\begin{array}{c}\text { Treatment } \\
\text { Cost (\$) }\end{array}$ & $\begin{array}{r}\text { Expected } \\
\text { Impact (\$) }\end{array}$ \\
\hline 1 & $\mathrm{x}$ & & & & & & 0 & 430 \\
\hline 2 & $\mathrm{x}$ & & & & & & 0 & 3,728 \\
\hline 3 & $\mathrm{x}$ & & & & & & 0 & 0 \\
\hline 4 & $\mathrm{x}$ & & & & & & 0 & 3,347 \\
\hline 5 & $\mathrm{x}$ & & & & & & 0 & 0 \\
\hline 6 & $\mathrm{x}$ & & & & & & 0 & 0 \\
\hline 7 & $\mathrm{x}$ & & & & & & 0 & 3,575 \\
\hline 8 & $\mathrm{x}$ & & & & & & 0 & 929 \\
\hline 9 & $\mathrm{x}$ & & & & & & 0 & 0 \\
\hline 10 & $\mathrm{x}$ & & & & & & 0 & 4,025 \\
\hline 11 & $\mathrm{x}$ & & & & & & 0 & 1,400 \\
\hline 12 & $\mathrm{x}$ & & & & & & 0 & 2,835 \\
\hline 13 & $\mathrm{x}$ & & & & & & 0 & 8,709 \\
\hline 14 & $\mathrm{x}$ & & & & & & 0 & 1,413 \\
\hline 15 & $\mathrm{x}$ & & & & & & 0 & 2,834 \\
\hline Total & & & & & & & 0 & $\$ 33,225$ \\
\hline
\end{tabular}


Table 6. Optimal fuel treatment plan based on an ecosystem services factor of 50 and fireline intensity threshold of $1000 \mathrm{~kW} / \mathrm{m}$.

\begin{tabular}{|c|c|c|c|c|c|c|c|c|}
\hline Area & NT & MT 20\% & MT 35\% & PF $100 \%$ & G $35 \%$ & G 20\% & $\begin{array}{c}\text { Treatment } \\
\text { Cost (\$) }\end{array}$ & $\begin{array}{c}\text { Expected } \\
\text { Impact (\$) }\end{array}$ \\
\hline 1 & $\mathrm{x}$ & & & & & & 0 & 21,499 \\
\hline 2 & & & & & & $\mathrm{x}$ & 7,280 & 0 \\
\hline 3 & $\mathrm{x}$ & & & & & & 0 & 0 \\
\hline 4 & & & & & & $\mathrm{x}$ & 7,280 & 402,575 \\
\hline 5 & $\mathrm{x}$ & & & & & & 0 & 0 \\
\hline 6 & $\mathrm{x}$ & & & & & & 0 & 0 \\
\hline 7 & & & & & $\mathrm{x}$ & & 12,740 & 0 \\
\hline 8 & $\mathrm{x}$ & & & & & & 0 & 46,426 \\
\hline 9 & $\mathrm{x}$ & & & & & & 0 & 0 \\
\hline 10 & & & & & $\mathrm{x}$ & & 12,740 & 0 \\
\hline 11 & $\mathrm{x}$ & & & & & & 0 & 70,007 \\
\hline 12 & $\mathrm{x}$ & & & & & & 0 & 141,727 \\
\hline 13 & $\mathrm{x}$ & & & & & & 0 & 435,433 \\
\hline 14 & & & & & $\mathrm{x}$ & & 12,740 & 0 \\
\hline 15 & & & & & $\mathrm{x}$ & & 12,740 & 0 \\
\hline Total & & & & & 50,960 & 14,560 & 65,520 & $\$ 1,183,187$ \\
\hline
\end{tabular}

Table 7. Optimal fuel treatment plan based on an ecosystem services factor of 100 and fireline intensity threshold of $1000 \mathrm{~kW} / \mathrm{m}$.

\begin{tabular}{|c|c|c|c|c|c|c|c|c|}
\hline Area & NT & MT 20\% & MT 35\% & PF $100 \%$ & G 35\% & G $20 \%$ & $\begin{array}{c}\text { Treatment } \\
\text { Cost (\$) }\end{array}$ & $\begin{array}{c}\text { Expected } \\
\text { Impact (\$) }\end{array}$ \\
\hline 1 & $\mathrm{x}$ & & & & & & 0 & 42,998 \\
\hline 2 & & & & & & $\mathrm{x}$ & 7,280 & 0 \\
\hline 3 & $\mathrm{x}$ & & & & & & 0 & 0 \\
\hline 4 & & & & & & $\mathrm{x}$ & 7,280 & 805,151 \\
\hline 5 & $\mathrm{x}$ & & & & & & 0 & 0 \\
\hline 6 & $\mathrm{x}$ & & & & & & 0 & 0 \\
\hline 7 & & & & & $\mathrm{x}$ & & 12,740 & 0 \\
\hline 8 & $\mathrm{x}$ & & & & & & 0 & 92,852 \\
\hline 9 & $\mathrm{x}$ & & & & & & 0 & 0 \\
\hline 10 & & & & & $\mathrm{x}$ & & 12,740 & 0 \\
\hline 11 & $\mathrm{x}$ & & & & & & 0 & 140,015 \\
\hline 12 & $\mathrm{x}$ & & & & & & 0 & 283,454 \\
\hline 13 & $\mathrm{x}$ & & & & & & 0 & 870,867 \\
\hline 14 & & & & & $\mathrm{x}$ & & 12,740 & 0 \\
\hline 15 & & & & & $\mathrm{x}$ & & 12,740 & 0 \\
\hline Total & & & & & 50,960 & 14,560 & 65,520 & $\$ \mathbf{\$ 2 , 3 0 0 , 8 5 7}$ \\
\hline
\end{tabular}

\section{Conclusions}

This work considers a two-stage stochastic integer programming (SIP) approach for fuel treatment planning under uncertainty in weather and fire occurrence. A two-stage SIP model is devised to minimize 
the here-and-now total costs of fuel treatment in the first-stage, and the total expected ecosystem services losses from potential future fires in the second-stage based on the treatment choices in the first-stage. The model includes four fuel treatment options: no treatment, grazing, prescribed fire, and mechanical thinning (no slash left onsite); and budgetary and labor constraints. A standard fire behavior model is used to estimate some of the parameters of the model and computes the areas burned under each scenario. The SIP model was implemented and applied to data for a study area in East Texas with 15 different treatment areas involving rural forests. The preliminary results of the study show that unless the expected ecosystem services values for an area outweigh the fuel treatment costs, no treatment is the best choice for the area provided that wildfire threat is relative low. The results also show that valuation of the areas in terms of ecosystem services values, probability of fire occurrence, and wildfire behavior have strong influence on fuel treatment choices.

This work considered known fuel levels and the study period was limited to one fire season. Future work will extend the SIP model to explicitly consider scenarios of vegetation growth over multiple study periods to simulate plant growth. The SIP model presented in this work ignored potential interaction between treatment areas. Therefore, another direction for future work is to include the possibility of interaction of fuel treatment areas and the associated impact in terms of making the optimal treatment plans. Finally, this study did not include fire suppression costs and simply focused on fuel treatment in relation to values at risk. Future work will include fire suppression costs as they may encourage fuel treatments so that future fires are easier to fight.

\section{Acknowledgments}

The authors wish to thank the Texas A \& M Forest Service (TFS) for providing the data used in this study. They are grateful to Curt Stripling for providing variable insights regarding fuel treatment planning for Texas.

\section{Author Contributions}

The author contributions to this paper are as follows: Kabli and Ntaimo led the efforts in developing the initial model, which was then revised based on contributions from Gan. Kabli did the software implementation of the model and conducted all the experiments. Based on his expertise, the ecosystem cost value estimates analysis was conducted by Gan. Finally, Kabli and Ntaimo led efforts regarding writing of the paper and Gan was responsible for making revisions.

All the authors contributed to this work and agree to be listed and approve the submitted version of this manuscript.

\section{Conflicts of Interest}

The authors declare no conflict of interest. 


\section{References}

1. Stephens, S.L.; Adams, M.; Handmer, J.; Kearns, F.R.; Leicester, B.; Leonard, J.; Moritz, M.A. Urban-wildland fires: How California and other regions of the us can learn from Australia. Environ. Res. Lett. 2009, 4, 1-5.

2. Dunbar, B. Climate Models Project Increase in U.S. Wildfire Risk, 2012. Available online: http://www.nasa.gov/topics/earth/features/climate-fire.html (accessed on 22 February 2014).

3. Gorte, R.W. Wildfire fuels and fuel reduction. In Congressional Research Service; Library of Congress: Washington, DC, USA, 2009.

4. Safford, H.D.; Schmidt, D.A.; Carlson, C.H. Effects of fuel treatments on fire severity in an area of wildland urban interface, angora fire, lake Tahoe basin, California. For. Ecol. Manag. 2009, 258, 773-787.

5. Bradstock, R.A.; Cary G.J.; Davies I.; Lindenmayer, D.; Price, O.F.; Williams, R.J. Wildfires, fuel treatment and risk mitigation in Australian eucalypt forests: Insights from landscape-scale simulation. J. Environ. Manag. 2012, 105, 66-75.

6. Hudak, A.T.; Rickert, I.; Morgan, P.; Strand, E.; Lewis, S.A.; Robichaud, P.R.; Hoffman, C.; Holden, Z.A. Review of Fuel Treatment Effectiveness in Forests and Rangelands and a Case Study form the 2007 Megafires in Central, Idaho, USA; General Technical Report RMRS-GTR-252; USDA Forest Service, Rocky Mountain Research Station: Fort Collins, CO, USA, 2011.

7. Finney, M.; Ghisu, T.; Spataro, W; Trunfio, G. A computational method for optimising fuel treatment locations. Int. J. Wildl. Fire 2008, 16, 702-711.

8. Finney, M.A. Design of regular landscape fuel treatment patterns for modifying fire growth and behavior. For. Sci. 2001, 47, 219-228.

9. Loehle, C. Applying landscape principles to fire hazard reduction. For. Ecol. Manag. 2004, 198, 261-267.

10. Wei, Y.; Rideout, D.; Spataro, W.; Kirsch, A. An optimization model for locating fuel treatments across a landscape to reduce expected fire losses. Can. J. For. Res. 2008, 232, 868-877.

11. Wei, Y. Optimize landscape fuel treatment locations to create control opportunities for future fires. Can. J. For. Res. 2012, 42, 1002-1014.

12. Rytwinski, A.; Crowe, K. A simulation-optimization model for selecting the location of fuel-breaks to minimize expected losses from forest fires. For. Ecol. Manag. 2010, 260, 1-11.

13. Minas, J.; Hearne, J.; Martell, D. An integrated optimization model for fuel management and fire suppression preparedness planning. Ann. Oper. Res. 2013, doi:10.1007/s10479-012-1298-8.

14. Minas, J.; Hearne, J.; Martell, D. A spatial optimisation model for multi-period landscape level fuel management to mitigate wildfire impacts. Eur. J. Oper. Res. 2014, 232, 412-422.

15. Trunfio, G.; Arca, B.; Ghisu, T.; Spataro, W. GPU-accelerated Optimization of Fuel Treatments for Mitigating Wildfire Hazard. Proc. Comput. Sci. 2013, 18, 966-975.

16. Kabli, M.R. Stochastic Programming Model for Fuel Treatment Management. Master's Thesis, Texas A \& M University, College Station, TX, USA, 2014.

17. Phytomas Growth Model (Phygrow) (Computer Software). Available online: http://cnrit.tamu.edu/ rsg/phygrow/ (accessed on 14 April 2015). 
18. Finney, M.A. FARSITE: Fire Area Simulator-model development and evaluation. In Res. Pap. RMRS-RP-4; U.S. Department of Agriculture, Forest Service, Rocky Mountain Research Station: Ogden, UT, USA, 2004; p. 47.

19. TWRA. The East Texas Fuels Mapping Project: Integration with the SWRA. Available online: http://www.southernwildfirerisk.com/mainprogram/2010/TFS $\backslash \% 20 \backslash \% 20$ East $\backslash \% 20$ Texas $\backslash \% 20$ Fuel $\mathbf{s} \backslash \% 20$ Mapping $\backslash \% 20$ Project.pdf (accessed on 28 April 2014).

20. Ntaimo, L.; Arrubla, J.; Stripling, C.; Young, J.; Spencer, T. A stochastic programming standard response model for wildfire initial attack planning. Can. J. For. Res. 2012, 42, 987-1001.

21. Anderson, H.E. Aids to Determining Fuel Models for Estimating Fire Behavior; General Technical Report INT-122; U.S. Department of Agriculture, Forest Service, Intermountain Forest and Range Experiment Station: Ogden, UT, USA, 1982; p. 22.

22. TFS. 2000 Fire Season Analysis and Fire in the South: A Report by the Southern Group of State Foresters, Texas Forest Service, 2000. Available online: http://txforestservice.tamu.edu/main/ default.aspx (accessed on 1 November 2010).

23. IBM ILOG CPLEX. User's Manual for CPLEX; IBM ILOG CPLEX: Mountain View, California, USA, 2012.

24. Ntaimo, L.; Arrubla, J.; Gan, J.; Stripling, C.; Young, J.; Spencer, T. A Simulation and Stochastic Integer Programming Approach to Wildfire Initial Attack Planning. For. Sci. 2013, 59, 105-117.

25. Simpson, H.; Taylor, E.; Li, Y.; Barber, B. Texas Statewide Assessment of Forest Ecosystem Services: A Comprehensive Analysis of Regulating and Cultural Services Provided by Texas' Forests, 2013. Available online: http://txforestservice.tamu.edu/uploadedFiles/Sustainable/enviro/ Publications/Reports/Ecosystem\%20Services\%20-\%20TX\%20Statewide\%20Assessment.pdf (accessed on 1 June 2015).

26. TRPA. Forest Fuel Reduction and Healthy Forest Restoration Plan for the Lake Tahoe Basin, 2007. Available online: http://www.fs.usda.gov/detail/ltbmu/news-events/?cid=STELPRDB5440876 (accessed on 27 April 2015).

27. Straitv, J. A Cost-Effectiveness Analysis of Hazardous Fuels Treatment Alternatives in Swasey Recreation Area, 2011. Available online: http://www.washingtoninstitute.net/ftpFiles/StudentFinal ProjectReports /TFM22/JeremyStrait.pdf (accessed on 20 March 2014).

28. USDA. Fall Prescribed Fire Operations Continue on Lake Tahoe's West and South Shores, 2013. Available online: http://www.fs.usda.gov/detail/ltbmu/news-events/?cid=STELPRDB5440876 (accessed on 20 March 2014).

29. USDA. Goats Grazing for Fuels Reduction on the Cleveland National Forest, 2013. Available online: http://blogs.usda.gov/2013/06/19/goats-grazing-for-fuels-reduction-on-the-clevelandnational-forest (accessed on 20 March 2014).

30. Duguy, B.; Alloza, J.; Roder, A.; Vallejo, R.; Pastor, F. Modelling the effects of landscape fuel treatments on fire growth and behavior in a Mediterranean landscape (eastern Spain). Int. J. Wildl. Fire 2007, 16, 619-632.

(C) 2015 by the authors; licensee MDPI, Basel, Switzerland. This article is an open access article distributed under the terms and conditions of the Creative Commons Attribution license (http://creativecommons.org/licenses/by/4.0/). 